\title{
MITOLOGIA AFRO-BAIANA: POSSIBILIDADE DE UMA PRÁTICA PEDAGÓGICA
}

\author{
Nilson Carvalho Crusoé Júnior ${ }^{1}$ \\ Nilma Margarida de Castro Crusoé ${ }^{2}$ \\ Cecília Conceição Moreira Soares ${ }^{3}$
}

\section{RESUMO}

Trata-se de um trabalho no qual elenca-se elementos contextuais que podem servir de ferramentas para que professores possam trabalhar com novas abordagens pedagógicas e perspectivas ideológicas distintas das tradicionais. Aponta a valorização do papel simbólico e estético da mitologia em geral, como sendo de importância cabal para a formação de educandos críticos e sensíveis às transformações sociais, no que tange à formação das culturas brasileira e baiana, em especial. Nesses contornos, perceber que o entendimento da mitologia afro-brasileira é essencial, pois formula e instiga vivências históricas daqueles que são herdeiros diretos dos grupos menos favorecidos da nossa sociedade.

Palavras-chave: Identidade baiana; Mitologia Afro-brasileira; Prática pedagógica.

\section{AFRICAN-BAHIAN MYTHOLOGY: THE POSSIBILITY OF A PEDAGOGICAL PRACTICE}

\begin{abstract}
This paper lists contextual elements which can serve as tools for teachers to work with new pedagogical approaches and different ideological perspectives of traditional. It points out the symbolic and aesthetic appreciation of the role of mythology in general, as being full of importance for the formation of critical and sensitive students to social, regarding the formation of the Brazilian and Bahian culture in particular. In such contours, realize that the understanding of African-Brazilian mythology is essential, because it formulates and instigates historical experiences of those who are direct heirs of disadvantaged groups in our society.
\end{abstract}

Keywords: Bahian identity; Afro-Brazilian mythology; Pedagogical practice

\section{Introdução}

Iniciamos por delimitar o conceito de mito:

Eliade afirma que o mito: Narra uma história sagrada; relata um evento que tenha acontecido na época primordial, a lendária época dos começos. Dito de outro modo, o mito nos conta como, pelos feitos dos Seres Sobrenaturais, uma realidade veio a existir, seja a realidade no seu total, o cosmos, ou apenas um fragmento de realidade. [...]. Uma vez que o mito relata os gestos dos Seres Sobrenaturais e a manifestação dos seus 
poderes sagrados, torna-se o modelo exemplar de todas as atividades humanas. (ANDERSON, 1996, p. 101).

Aquiles, herói mitológico grego, um guerreiro nato, destemido, capaz de combater milhares de soldados inimigos, ídolo a ser seguido, aquele que possui o Aretêt ${ }^{4}$ Com todos esses atributos, Aquiles mistura o lado humano/mortal com o lado semideus/imortal, e serve de parâmetro para uma sociedade que vivia para a guerra assim como o "rio desemboca no mar".

Citando esse exemplo de herói estamos nos reportando na verdade a um momento onde todas as civilizações viviam em torno de símbolos mitológicos, os quais consolidavam uma dinâmica social, que dominou por séculos, e sem os quais provavelmente tais civilizações não teriam deixado memória.

$\mathrm{O}$ uso do mito e da mitologia enquanto resgate mnemônico é atributo social e historicamente perceptível, e isso diz respeito a qualquer povo e/ou cultura, em suas várias e complexas formas.

As civilizações ocidentais buscam orientar seus paradigmas e suas estéticas de vida a partir das civilizações ditas clássicas da antiguidade, como: Grécia e Roma, e com isso "traduzem" o seu modus vivendi para o mundo, tentando moldá-lo à sua vontade, buscando construir suas hegemonias, principalmente de classe, de raça, e de gênero.

Sabemos também que civilizações, sejam elas quais forem, em que tempo for, e de onde vierem, são exemplos de formação de sociedades dominadoras e conquistadoras, ainda que de modos distintos, sendo a História Tradicional a maior prova desse fato.

Não nos cabe nesse instante trabalhar o conjunto de fatores históricos que deram forma às civilizações durante a história, mas deixar salientado que, de uma forma geral, todas elas se utilizaram da mitologia e dos mitos como formas de representações estéticas fundamentais, e é a partir desse pressuposto que iremos trabalhar com a mitologia afrobrasileira.

Acreditamos também ser de suma importância a construção, a partir dessa mitologia, de novos paradigmas estéticos que nos imprimam outras variantes teóricas e novas propostas pedagógicas para serem aplicadas nas escolas em nosso país, mesmo porque a Lei 10.639/03 e a posterior obrigatoriedade do ensino das culturas indígenas no Brasil, indicam que ações políticas estão sendo tomadas no sentido de tornar o processo ensino-aprendizagem mais inclusivo com relação as diferenças que compõem o conjunto da sociedade, e nós, enquanto docentes, temos que tomar a dianteira nesse processo, o que envolve formação adequada para lidar com os sujeitos que chegam à escola.

\section{O olhar etnológico de Roger Bastide acerca da simbologia das religiões africanas}

Bastide (1968), referindo-se às questões africanas e afro-brasileiras no processo histórico que delineia as civilizações ocidentais, destaca o papel fundamental da religiosidade de origem africana na preservação de valores culturais e da memória frente às religiões dos povos ditos civilizados. Para ele, o

Ocidente substitui cada vez mais, e sobretudo a partir de Descartes, a ordem mítica por uma ordem artificial mais ou menos fabricada pelos matemáticos ou gramáticos, enquanto a África continua a conservar nas 
palavras seus valores subjetivos, coletivos e culturais. O africano vê em tudo que percebe através dos seus sentidos coisa diversa da que ele vê descobre o Outro, isto é, o Sagrado, através dos minerais, vegetais ou animais[...]. (BASTIDE, 1968, pp.7-8, grifos nossos).

O que mais chama atenção nessa colocação é o fato do autor estar preocupado com o tipo de relação que se estabelece entre os sujeitos e as religiões. Para Bastide (1968) fica evidenciado que no mundo civilizado europeu tal sujeito cria uma linguagem que o distancia do sagrado, na medida em que o mesmo torna-se "artificializado", levando o homem à uma relação relativamente mecanicista com o sagrado.

Em relação aos símbolos sagrados africanos, o autor indica uma percepção distinta da ordem das coisas, pois para ele é como se o sagrado nas religiões africanas compusesse a vida quotidiana indissociável, uma vivência absoluta, complementar ao devir social e cultural, intermediada pelos sentidos. Podemos ver isso claramente em outro trecho do texto, no qual Bastide complementa a ideia anterior: “[...] Não é a palavra do homem que significa e circunscreve os objetos; são os objetos ou coisas, que são "palavras" para o africano[...]". (BASTIDE, 1968. p.8)

A identificação de uma relação íntima, consubstanciada numa proximidade que faz do sujeito mais do que um crente, um "vivente", por assim dizer, é aquilo que distingue as relações das pessoas com os deuses e/ou santos nas estruturas de civilização ocidentais e nas religiões de origem africana, segundo o autor.

Essa "intimidade" permite ao praticante das religiões de origem africana perceber a ordem natural como complemento da ordem social, permite na verdade, enxergar-se também como parte de uma ordem cósmica original, o que tende a torná-lo mais sensível ao mundo que o cerca.

Em outro trecho em que compara o sentido de distanciamento e aproximação respectivamente, do sujeito para com as religiosidades ocidental e africana, afirma:

A verdadeira religião africana é, ao contrário, expressãa de uma ordem, de uma harmonia entre os homens e as coisas, dos homens entre si, como objetos. As participações são os conjuntos das malhas sutis que ligam esses compartimentos do real, uns com os outros, afim de tecê-los em uma túnica inconsútil; constituem o cosmo organizado[...] (BASTIDE, 1968.p.12, grifos nossos).

$\mathrm{Na}$ verdade a intenção do autor é demonstrar que as "significações" das religiões civilizadas do ocidente foram substituídas, a partir do advento da racionalidade na era moderna, por linguagens pretensamente "dissociantes", ou seja, o homem ocidental civilizador se afasta do seu sentimento religioso mais natural por assim dizer, e assume uma postura de "leitor" dos sinais sagrados, o porta voz, em última instância, da "verdadeira" e civilizadora religião.

Sobre esse aspecto evidencia-se que:

O homem temente, que se interroga sobre sua salvação, não procura em seu derredor descobrir um pensamento cósmico que seria o de Deus - ele aí busca um conjunto de sinais, tais como o êxito profissional, a estima de sua comunidade, o bom funcionamento de sua vida, que testemunharão sua eleição divina. Os acontecimentos formam uma cadeia de palavras cujo significado reside na própria cadeia, significativa 
para o homem que questiona para si mesmo mas que perdeu toda significação universal e transcendente. (BASTIDE,1968, p.8, grifos nossos).

Podemos falar sinteticamente que, ao tratar das relações religiosas no Ocidente e na África, tendo em vista buscar uma origem para o entendimento dos paradigmas constitutivos de duas das origens culturais formadoras do nosso meio social, Roger Bastide (1968) nos traz informações relevantes para a construção de uma consciência crítica acerca não só das religiões enquanto espaços de cultos, mas de novas perspectivas de análise das culturas afro-brasileiras.

Isso é fundamental para que possamos redimensionar os nossos olhares acerca das contribuições culturais de origem africana para o Brasil e para o mundo, e mais, podemos depreender desse texto que a mitologia afro-brasileira é transformadora de realidades, visto que ela se baseia no sentimento, na harmonia natural entre o homem e o meio, ela "visualiza" a essência que o homem vem perdendo a partir de uma racionalidade individualista, a qual pode ser resumida no que Weber chamou de: "O Espírito do Capitalismo" (WEBER, 2002).

\section{Concepções identitárias distintas: o confronto entre a Oralidade e a Escrita}

Saindo agora da questão religiosa citada anteriormente, e ainda na esteira da "comparação" entre as culturas ditas civilizadas e as culturas de origem africana ${ }^{5}$ e afrobrasileira $^{6}$, tentaremos expor um problema existente no quotidiano da nossa realidade como exemplo de que as formações culturais divergem em outros campos da vida social.

Num artigo intitulado: "Terras de uso comum: oralidade e escrita em confronto", (GUSMÃO, 1995) existe uma discussão bastante importante, originária das questões judiciais relativas às terras de remanescentes de quilombolas no Brasil.

Tendo em vista uma análise baseada na ideia de que as culturas de origens negra e branca possuem modelos sociais distintos, provoca-se o leitor no sentido de se entender a questão por olhares diversos e menos pragmáticos.

Galgada numa percepção de que as culturas negras possuem como base formadora principal a Oralidade e as civilizações se baseiam na Escrita, a autora procura construir uma outra ideia de Direito e Justiça, preocupando-se com isso em dar um suporte de legalidade às aspirações das comunidades remanescentes de quilombolas.

Em caminho contrário à legislação e tendo por certo que o confronto entre oralidade e escrita não se restringe aos fatos "contidos na forma da lei" versus os significados das práticas costumeiras, que pretendo discutir aqui a oralidade de grupos negros e camponeses como espaço de contra-poder e de expressão múltipla (...) a escrita representa a forma de expressão mais acabada da sociedade inclusiva, que a utiliza para exercer um domínio e poder sobre aqueles que dela não dispõem.(GUSMÃO,1995, p.116)

Chegamos agora a um ponto fundamental da nossa análise, já que o que está explicitado acima é o fato de que existem apenas culturas diferentes, mas não superiores umas às outras, posto que, o que verdadeiramente está em confronto são 
modelos diferentes de apropriação da realidade, sendo os negros os portadores de uma memória cultural oral e significante, e os brancos os portadores de práticas civilizatórias de dominação.

Para Gusmão (1995), a Oralidade se apresenta historicamente como um fator de resistência ${ }^{7}$ permanente, criando uma via de sobrevivência constante para as culturas negras no Brasil, pois,

\begin{abstract}
Uma multiplicidade de recursos são criados e recriados constantemente como meio de garantir as formas de comunicação próprias do seu mundo, i.e, entre iguais e com o mundo do "outro". As linguagens dessa prática concreta são assim, formas de existir e resistir aos mecanismos desagregadores do mundo inclusivo. (GUSMÃO, 1995, p.117, grifo nosso).
\end{abstract}

A Oralidade dos remanescentes de quilombolas é um exemplo de como se pode construir identidades e permitir a perpetuação da memória histórica. Portanto, frente a uma realidade desagregadora e fortemente individualista, podemos, através da valorização dos aspectos inerentes às formas mitológicas de apreensão da realidade, formular novos conceitos e perspectivas de uma vida mais harmoniosa.

O respeito aos ancestrais tão fortemente presente nessas lutas pela posse da terra, e o fato concreto de terem sido eles que as deixaram de herança, e ainda, as formas de cultivo dessas mesmas terras, são elementos basilares da mitologia afro-brasileira, estando todos presentes em relatos mitológicos sobre os quais falaremos mais adiante.

O confronto entre a Oralidade e a Escrita pode ser sintetizado então como uma luta entre sociedades e culturas distintas, e mais, uma luta identitária, onde a oralidade, e sua suposta informalidade, firmam laços de sobrevivência importantíssimos, sem os quais geralmente esses povos já teriam sucumbido diante do processo civilizador (ELIAS, 1994).

\title{
A questão identitária na Afro-baianidade nagô
}

Em artigo versando sobre a questão identitária nas comunidades de origem nagô (FREITAS, 1995), observamos uma abordagem explicativa acerca da ideia construtiva de "identidades" dentro de uma realidade afro-baiana, a partir de uma pesquisa criteriosa e bem interessante.

Ele utiliza as noções básicas acerca de conceitos como: personalidade, caráter e identidade, usando autores consagrados da psicologia, da psicanálise e da antropologia cultural $^{8}$, para exemplificar que os critérios adotados por tais autores não podem ser aplicados de forma direta à análise de tais conceitos quando se tratar de comunidades de origem afro-baiana, pois

O conceito de personalidade nas comunidades afro-baianas de origem nagô se afasta significativamente daqueles adotados pela psicologia científica. Inclusive quando esta admite a pertinência de elementos místicos como o faz na doutrina de Jung. (FREITAS, 1995, p.84).

Esse autor retoma em parte a discussão suscitada anteriormente quando se "compara" elementos próprios das civilizações com outros oriundos das culturas africanas. A diferença principal se dá porque nesse momento a questão abordada se coloca no âmbito 
dos estudos das particularidades psicossociais por assim dizer, pois ele parte de percepções comportamentais que se restringem ao exemplo das comunidades afro-baianas de origem no candomblé nagô 9 .

Portanto, tendo como suporte o recorte dado a partir desse texto, podemos falar agora de como entender a formação de uma identidade baseada em aspectos mitológicos de origem africana, uma vez que "Toda e qualquer pesquisa relativa à identidade no culto nagô é circundada por três dificuldades básicas: a transmissão oral do conhecimento; o culto do segredo; e a inadequação do referencial utilizado." (FREITAS, 1995.p.85)

Essa ideia reforça a tese de que as diferenças culturais, e mais, as diferenças na apreensão da realidade e na transmissão dos conhecimentos, não necessariamente devem ser hierarquizadas no sentido dominante-dominado ou vice-versa, uma vez que se trata tão somente de diferenças nos modos de vida e de transmissão de conhecimento, o que não passa por hierarquias, sejam elas de que ordens forem.

Por conseguinte, entender as questões comportamentais de grupos de pessoas de origem africana e afro-brasileira, - questões essas que estão no cerne das suas culturas-, não é tarefa simplista, já que a sua complexidade é latente, diante do que já foi dito até aqui.

No texto de Freitas (1995) há uma colocação que reforça tudo o que foi colocado anteriormente:

\footnotetext{
$\mathrm{Na}$ cultura dos egbe $e^{10}$ o conhecimento flui através dos processos de integração homem/natureza: a palavra falada, o gesto, o movimento, a dança, a cantiga, o ritmo, a cor, a plasticidade formal e a emblemática, a comida, o tato e as texturas. Os apelos. As conjunções de todos os sentidos. (FREITAS, 1995, pp.85-85, grifo nosso)
}

Diante do exposto vemos que a mitologia afro-brasileira e baiana por extensão é rica em sentidos e guardiã de uma memória a ser explorada de forma consciente e construtiva. Nada deve ser feito no sentido de garantir qualquer inserção cultural de comunidades de origem africana no Brasil sem levar em consideração tais condições. É preciso ter sensibilidade e vontade política para tanto.

O Projeto Pedagógico Irê Ayó: uma possibilidade de prática pedagógica afro-baiana

O comportamento solidário encontrado nos mitos, e até nas situações paradoxais, se constituem em bens coletivos, e acreditamos no seu funcionamento como perspectiva de transformar a Educação das Relações Étnico-Raciais para o ensino de História e Cultura AfroBrasileira e Africana em uma possibilidade de a criança ganhar qualificação e respeito à sua diferença, conquistando visibilidade, expressando-se e sendo considerada. Acreditamos que é possível fazer configurar, finalmente, a identidade e a consciência pluricultural na escola, que atingirá seu objetivo de construir cidadãos autônomos e coletivos. (MACHADO, 2003, p.11).

O Terreiro de Candomblé Ilê Axé Opô Afonjá, localizado no Bairro de São Gonçalo do Retiro, na Cidade de Salvador, na Bahia, é um local que reúne um universo de valores materiais e simbólicos bastante representativos para o chamado "Povo de Santo", sendo composto de construções diversas inseridas num ambiente natural muito aprazível. 
Sob o comando de Mãe Stella de Oxóssi, o Terreiro possui oficinas de música, literatura e outras atividades voltadas para a inserção da comunidade, e principalmente das crianças, no universo como um todo, e mais, lá se realiza toda uma gama de vivências coletivas que mantêm vivas a memória afro-brasileira.

A presença de uma Escola Municipal de nome Eugênia Anna dos Santos (Mãe Aninha, primeira sacerdotisa do Opô Afonjá), que, em parceria com o Terreiro, fornece o ensino fundamental à crianças, estando localizada dentro do seu espaço, confirma a ideia de uma noção coletivista de vida, e práticas sociais comunitárias.

Nessa escola vêm sendo implantado há algum tempo um projeto de pedagogia onde o idioma Yorubano e a Mitologia afro-brasileira são usados na formação das crianças, sendo portanto um projeto pioneiro de ação política/pedagogizante para a construção de uma identidade de origem africana e afro-brasileira no seio da nossa sociedade.

Capitaneado e idealizado pela Profa. Dra. Vanda Machado, o projeto Irê Ayó usa as narrativas mitológicas dos negros como elemento estruturante de uma formação cidadã onde os alunos possam obter o conhecimento através da intermediação da sua própria memória passada, uma vez que considera-se a essência da vida afro-brasileira como sendo fruto direto dessa memória.

Machado (2003) ressalta a viabilidade desse projeto a partir da ideia de que,

Compreender a mitologia africana passa pela necessidade de apreensão de outras realidades. O ser humano não foi construído de um único elemento da natureza. A construção de um ser síntese do mundo, síntese de elementos universais. O pensamento africano, destacadamente a mitologia, serve como reflexão para aproximação ou reconciliação da cultura com a Ciência, com a Filosofia, com a Psicologia moderna e com $\boldsymbol{a}$ vida, na elaboração de saberes e fazeres e as práticas educacionais. (MACHADO, 2003, p. 6, grifo nosso).

Ao inserir a memória africana a partir da sua mitologia na educação das crianças obtêm-se novos paradigmas estéticos, os quais, construídos em conjunto com uma identificação entre a criança e a narrativa, abre-se nova perspectiva de conhecimento, e mostra que as culturas que foram escravizadas no passado colonial são possuidoras de historicidade, o que passa para o presente vivido pelas crianças como uma ideia de que elas são frutos dessa historicidade.

$\mathrm{Na}$ verdade, além de buscar essa constituição histórica, tenta-se afirmar o passado não como um tempo de mazelas, apenas, mas um tempo de resistência, onde os mitos, sejam eles representados por pessoas como Zumbi, por exemplo, um herói já mitificado (ANDERSON, 1996) e vangloriado da resistência à escravidão, e/ou Ogum, o Orixá das vanguardas, aquele que abre os caminhos para a humanidade, expoentes dessa resistência.

Com isso vemos que a mitologia afro-brasileira torna-se parte constitutiva do universo do conhecimento, pois seus relatos saem de um plano particular de culturas em especial, como a nagô no caso, e se alastram pelo universo, pois Ogum, por exemplo, é símbolo de vanguarda da coletividade e não somente um referencial pertencente aos nagôs.

No espaço do Terreiro, ocorre uma convergência de laços comunitários e um terreno propício para o conhecimento através da mitologia. Isso se dá porque,

A tradição cultural vivenciada no terreiro proporciona aos seus participantes um guia indispensável para a organização de suas vidas. 
Uma comunidade de terreiro, portanto, pode ser entendida como um grupo de indivíduos portadores de reações agregadoras, solidárias, festivas, repetidas sempre como uma novidade. Essa é uma predição, é um requisito para qualquer espécie de vida organizada. Esse é um dos valores expressos nos contos míticos. É só despertá-lo nas convivências. (MACHADO, 2003, p. 7, grifo nosso).

Percebemos então que o projeto pedagógico em questão encontra na comunidade do Terreiro uma caixa de ressonância por assim dizer, uma vez que possui as condições materiais e espirituais basilares para o entendimento da mitologia africana e afro-brasileira, o que contribui muito para a construção de novos modelos estéticos importantes para as crianças negras e pobres, principal público a ser atingido pela pedagogia transformadora do projeto Irê Ayó.

Esse contexto reforça a ideia de que

Os mitos de matriz cultural africana favorecem a construção da identidade da criança afrodescendente, permitindo-lhe a condição de ser, pertencer e participar de seu grupo étnico, reconhecendo os valores da sua comunidade, o que pode lhe servir como exemplo positivo e estímulo para a participação na comunidade. (MACHADO, 2003. pp.10-11).

Experiência válida e interessante, esse projeto por certo contribui para a reformulação de pedagogias, principalmente aquelas oriundas de políticas públicas. Ele elabora perspectivas estéticas distintas e colabora para a autoafirmação negra de uma maneira salutar. Na verdade, o Projeto Pedagógico Irê Ayó oportuniza espaço para se pensar o imaginário e a cultura afro-brasileira como modelos de vida tão válidos como qualquer outro.

\section{A dimensão estética da educação e a cultura afro-brasileira}

Finalmente podemos dizer que há uma dimensão estética associada a cada um dos aprendizados que podem advir das práticas que até agora colocamos em confronto, quais sejam: a prática pedagógica hegemonicamente ocidentalista, baseada em objetivos pragmáticos e individualizantes; e uma prática pedagógica que ainda está por ser construída, galgada na mitologia e na sua base oral. Assim como, todas as outras reivindicações provenientes de outras ordens que compõe o cenário social brasileiro, as quais, tem também, por finalidade, resgatar a memória e os feitos dos oprimidos, inserindoos ativamente na história e na educação escolarizada.

A dimensão estética da prática pedagógica ocidentalista funda-se no pensamento discursivo, buscando uma lógica, e valorizando aspectos como: sequencialidade, objetividade e linearidade. Ela elabora um modelo de vida no qual as hierarquias sociais servem de pretexto para a dominação, pois separa os dois eixos relacionais do ser humano, a razão e a emoção.

Ao separar esses eixos relacionais, hierarquizando-os, constroem-se referências simbólicas diante das quais: a oralidade perde espaço para a escrita e o sentimento para a razão. Consequentemente, as culturas estruturadas sob símbolos mitológicos são vistas enquanto inferiores e passíveis de serem civilizadas. 
É importante salientar também o seguinte: ainda que, na "Antiguidade Clássica", o Ocidente vivenciasse seu universo através da mitologia, esse tipo de simbologia e explicação da ordem universal, foi superado na modernidade pelo racionalismo, corolário da evolução da espécie humana, no entender das culturas de origem cristã da Europa colonialista.

Partindo do pressuposto de que as culturas ditas civilizadas se impõem pela sua estética de vida racionalista, podemos inferir que todos os modelos vivencias que dominam o mundo ocidental levam em conta certos padrões socioculturais que dificultam a autoafirmação do negro e de sua estética.

Existe uma lógica de que "O racionalismo de nossa civilização olha com maus olhos tudo o que possa alterar suas bases estabelecidas, tudo que possa propor uma nova ordem." (DUARTE JÚNIOR, 1988, p.101). Com isso temos a ideia de que, praticar uma nova pedagogia que traga na sua esteira a dimensão estética afro-brasileira, é construir novos paradigmas, baseados em propostas didáticas necessariamente de "enfrentamento".

Por conseguinte a construção de elementos cuja estética se associe a identidade afro-brasileira torna-se um contraponto importante à essa dominação racionalista, já que os mesmos vislumbrariam o surgimento de novos valores culturais, enraizados em novos sentidos, o que tornaria a história desses povos diferente, aliás, torná-los-iam "povos históricos", se analisarmos a questão dentro da "lógica" ocidentalista.

Como exemplo disso podemos nos reportar a arte enquanto elemento estético e pedagógico importante, e dizer que a mesma, assim como a mitologia, pode ser entendida como um novo paradigma estético construtor de culturas e identidades singulares. Através da afirmação a seguir, vemos reforçada a ideia colocada no início do texto de que não existem hierarquias culturais dadas, elas são construções sociais advindas da dominação ocidental e do seu processo civilizatório:

[...] Cada cultura possui uma forma própria de sentir um determinado sentimento básico, comum a todos os seus membros; tal sentimento caracteriza o que chamamos de "personalidade de base" ou "personalidade cultural" (DUARTE JÚNIOR, 1988, p.108)

Estamos nós, portanto, diante de uma grande luta, que coloca frente a frente dimensões estéticas distintas, valores e percepções de mundo conflitantes, e, para que nós possamos empreender novos paradigmas pedagógicos em nossa profissão de educadores, temos que nos tornar militantes engajados, profissionais em educação, críticos e voltados para tais perspectivas transformadoras.

\section{Considerações Finais}

Ao despertarmos, com a narrativa mitológica, a memória afrodescendente, estamos adentrando um caminho novo e profícuo de conhecimento e apreensão da realidade. As sociedades geralmente agrárias da África pré-colonial não encontravam-se paradas na História quando os "civilizadores" as escravizaram, e nem eram simples modelos tribais "incultos", eram modelos societários complexos e de valores culturais imensuráveis.

Por conseguinte, tudo o que advier dessa mitologia, na verdade mitologia recriada no Brasil a partir das condições da escravidão, é de muito valor, servirá de referencial, de 
modelo de vida, em síntese, de elemento construtor de identidades, o que é mais do que bem-vindo dentro de um modelo estético de tradição escolástica e racionalista.

A desconstrução de temporalidades históricas eurocêntricas e de suas inerentes ideologias de dominação deve ser considerada fator primordial na elaboração de propostas políticas e pedagógicas que incluam todo o conjunto da nossa sociedade, e, certamente, o Projeto Irê Ayó caminha nesse sentido.

Por fim, diríamos que a construção de novos paradigmas identitários para as populações de origens negra e indígena,- Brasileiras, portanto -, pode se dá através da via mitológica, onde podemos resgatar memórias e demonstrar a historicidade latente dessas populações, que sempre foram marginalizadas dentro do processo civilizador (ELIAS, 1994) imprimido no Brasil a partir da Era Moderna, o que daria forma à uma nova dimensão estética de vida, menos excludente com certeza.

\section{Referências}

ANDERSON, Robert. O Mito de Zumbi: implicações culturais para o Brasil e para a diáspora africana. Revista Afro-Ásia, Salvador: UFBA/CEAO. v. 17. p. 99-119, 1996.

BASTIDE, Roger. Religiões Africanas e Estruturas de Civilização.Revista Afro-Ásia, Salvador: UFBA/CEAO, v. 6 e 7. p. 5-16, 1968.

DUARTE JÚNIOR, João Francisco. Fundamentos estéticos da educação. Campinas, SP: Papirus, 1988, p. 95-119.

ELIAS, Norbert. O Processo Civilizador: Formação do Estado e Civilização (Vol.2). Rio de Janeiro: Jorge Zahar Editora, 1994.

FREITAS, Edmundo Leal de. Personalidade: identidade nas comunidades afro-baianas. Revista Afro-Ásia, Salvador: UFBA/CEAO, v.16, p. 80 - 89,1995.

GIROUX, Henry. Teoria crítica e resistência em educação. Petrópolis, Vozes, 1986.

GUSMÃO, Neusa Maria Mendes de. Terras de uso comum: oralidade e escrita em confronto. Revista Afro-Ásia, Salvador: UFBA/CEAO, v. 16. pp. 116-132, 1995.

LUZ, Marco Aurélio. Arkhé e Axexé: linguagem e Identidade. In Cultura negra em tempos pós-modernos [online]. 3. ed. Salvador: EDUFBA, 2008. 181 p. Disponível em: http://books.scielo.org/id/39h/pdf/luz-9788523209063-11.pdf. Acesso: 14 set. 2015.

MACHADO, Vanda. Mitos afro-brasileiros e vivências educacionais. Secretaria Municipal de Educação e Cultura (SMEC), Salvador-BA, 2003.

MURARI, Juliana Cristhina et al. Objetivos e Características da Educação Homérica: Uma reflexão sobre o conceito de Areté. ANAIS do IX Congresso Nacional de Educação EDUCERE / III Encontro Sul Brasileiro de Psicopedagogia - 26 a 29 de outubro de 2009 - PUCPR. Disponível em: http://www.pucpr.br/eventos/educere/educere2009/anais/pdf/2562_1928.pdf. Acesso: 14 set. 2015. 


\section{WANDERLEY, Alba Cleide Calado \& AQUINO, Mirian de Albuquerque. A construção da identidade afro-brasileira em histórias de vida, lutas e resistências. SAECULUM - Revista de História [21]; João Pessoa, jul./dez. 2009, p. 181-193.}

\section{WEBER, Max. A Ética Protestante e o Espírito do Capitalismo. Coleção “A obra-prima} de cada autor". São Paulo: Martin Claret, 2002.

\section{Notas}

${ }^{1}$ Doutor e Mestre em História Social - UFBA. Pesquisador do Grupo de Estudos e Pesquisa em Práticas Educacionais (GEPPE). Professor da Rede Estadual da Bahia e Ex-professor dos cursos de Pós-graduação em Serviço Social e Seguridade Social, e Serviço Social e Saúde - PÓS-GRAD / UNYAHNA; da Academia de Polícia Militar da Bahia; e da Pós -graduação em Gestão de Segurança Pública - UNIME-FETRAB. Contato: crusoejunior@hotmail.com

${ }^{2}$ Doutora em Educação -UFRN com Estágio Doutoral na Universidade de Coimbra, Portugal. É pesquisadora e professora Titular da Universidade Estadual do Sudoeste da Bahia- UESB. Desenvolve pesquisa, ensino e extensão na área de Prática Pedagógica em espaços educacionais. Líder do Grupo de Estudos e Pesquisa em Pratica Pedagógica em Espaços Educacionais (GEPPE), e do Comitê Editorial da Revista Práxis Educacional, do Programa de Mestrado em Educação (PPGEd/Uesb). Coordenadora e professora do Programa de Mestrado em Educação (PPGEd/Uesb). Contato: nilcrusoe@uol.com.br

${ }^{3}$ Doutorado em Antropologia pela Universidade Federal de Pernambuco (2009). Doutorado Sanduíche na Facultad de Cíencías Socíales da Universidade de Salamanca- Espanha ). Pesquisadora no Grupo de Estudos e Pesquisa em Pratica Pedagógica em Espaços Educacionais (GEPPE), da Universidade Estadual do Sudoeste da Bahia.ceciliasoares@yahoo.com.br

4 No tocante a esse conceito, Murari et al (2009, p. 9859-9860) evidencia que: É impossível considerar os ideais de formação humana entre os gregos sem destacar um conceito fundamental para eles: o conceito de areté. [...] . Não temos na língua portuguesa uma tradução exata desse termo, embora seja muito comum traduzi-lo por virtude. Isso, porém, pode levar a pensar que o ideal educacional grego compreendia apenas uma natureza ética, quando na realidade ia muito além disso. O termo que melhor traduziria a areté seria excelência; contudo, essa palavra, ainda que expresse preceitos morais, carrega consigo uma multiplicidade de significados que precisam ser abordados, pois é ela que fundamenta o modo de pensar a educação na Grécia pré-arcaica.

${ }^{5}$ Essa origem africana, aqui, se refere aos estudos realizados por Roger Bastide sobre os ritos de origem Nagô/Yourubá.

${ }^{6}$ Para Wanderley \& Aquino (2009, p. 182): Os afro-brasileiros seriam afrodescendentes que construíram sua identidade africana no espaço brasileiro. Pode ser dito também que afro-brasileiro é aquele que tem de si e em si a imagem de ser africano no Brasil, em todas as circunstâncias. É aquilo que uma pessoa considera determinante, ou seja, a identidade que o sujeito assume, da qual se apropria e torna de si próprio.

${ }^{7}$ Resistência aqui se refere a ideia de resistência desenvolvida por Henry Giroux em Teoria crítica e resistência em educação. Petrópolis, Vozes, 1986.

${ }^{8}$ O autor utiliza algumas ideias de autores como: Gordon Willard Allport (1897-1967); Sigmund Freud (1856-1939) e Carl Gustav Jung (1875-1961).

${ }^{9}$ Acerca dessa referência o autor esclarece no texto: Adota-se aqui a designação nagô, isolada, embora saiba se da contribuição significativa e indissociável na elaboração do modelo estrutural desse candomblé prestada pelos fon, genericamente conhecidos como jeje. Op. Cit, p. 81, nota de rodapé 5.

${ }^{10}$ Para Luz (2008, p. 89), as comunidades-terreiro, egbé, se constituem em bem organizadas instituições compostas de um espaço sócio-religioso e arquitetônico próprio e caracterizado por uma população flutuante de seus membros que ali comparecem conforme determinada temporalidade litúrgica.

Recebido: fevereiro-16 março-16 